\title{
Epidemiology of Parkinson's Disease
}

\author{
A.H. Rajput
}

\begin{abstract}
Epidemiology of parkinsonism for 13 years (1967 to 1979) in Rochester, Minnesota is evaluated. For each patient, two age- and sex-matched controls with comparable medical follow-up (mean 40 years before diagnosis) were selected from the same community. Smoking habits, dementia, acute and chronic illnesses and mortality patterns in the two groups are compared. The annual incidence rate was $20.5 / 100,000$, which is virtually unchanged from previous reports on Rochester population. Cigarette smoking habits of cases and the controls before the index date were not significantly different. Prior to diagnosis of Parkinson's disease, dementia was diagnosed significantly more frequently among the patients than the controls $(P=0.048)$. After diagnosis of parkinsonism dementia emerged nearly three times more frequently in patients than among the controls. Mortality rate in the entire parkinsonian population was similar to that reported from the same community between 1935 and 1966 . Only $50 \%$ of the patients were treated with levodopa. Among those treated with levodopa the mortality rate was comparable to their controls. Because there were no definite criteria for administering levodopa therapy, higher frequency of dementia and prolonged survival in those treated with this drug could be attributed to the bias of case selection for treatment.
\end{abstract}

RÉSUMÉ: Nous évaluons l'épidermilogie du Parkinsonisme à Rochester, Minnesota, sur une période de 13 ans (1967-1979). Pour chaque patient nous avons choisi deux témoins du même sexe et du même âge ayant un suivi médical identique. Nous comparons ainsi les habitudes de fumeur, la démence, les maladies aigues et chroniques et les patterns de mortalité. Le taux d'incidence annuel était de 20.5/1,000,000, soit le même que lors des études antérieures. Les habitudes de fumeur des patients et des témoins, avant la date index, n'étaient pas significativement différentes. Avant le diagnostic de Parkinson il y avait significativement $(p=0.048)$ plus de démence que chez les témoins. Après le diagnostic, la démence était trois fois plus fréquente chez les patients. Le taux de mortalité des patients est le même que celui observé entre 1935 et 1966. Cependant seulement $50 \%$ des patients avaient reçu la Lévodopa. Chez ceux-ci le taux de mortalité était semblable aux témoins. Comme il n'existait pas de critères pour administrer la Lévodopa, l'observation d'une fréquence plus élevée de démence et d'une survie plus longue chez les sujets traités est probablement due au choix des patients.

Can. J. Neurol. Sci. 1984; 11:156-159

Since widespread use of levodopa in the late 1960's there has been a renewed interest in the epidemiology of Parkinson's disease. In the earlier years of clinical trials it was thought that the drug may slow down the progressive deterioration in some parkinsonian patients, (Cotzias, 1971), and because of the excellent symptomatic control, it was predicted that the mortality rate on this treatment would decline. If the life expectancy increased the prevalence rate of parkinsonism would gradually rise.

The effects of cigarette smoking on subsequent development of parkinsonism has received considerable attention in recent years. (Hammon, 1966; Kahn, 1966; Baumann et al., 1980) but the issue has not been settled so far. Dementia in parkinsonian patients and its relationship to levodopa therapy is another aspect that needs more definitive answers.

This paper is based on work carried out during a sabbatical period with Dr. L.T. Kurland in the Department of Epidemiology at the Mayo Clinic. Epidemiological studies on Parkinson's disease in Rochester, Minnesota for the period of 1935 to 1966 have been reported previously (Kurland, 1958; Nobega et al., 1967) and it was thought that studies on the same population after widespread use of levodopa would provide an opportunity to determine the effects of this drug in parkinsonian population.

\section{MethoDs}

I reviewed the original medical records on all Rochester residents suspected of having parkinsonism during the 13 year period from 1967 to 1979 . The date of onset of parkinsonism could not be accurately established but the date of diagnosis was available in the records. For each patient, two age- and sex-matched Rochester residents who attended the same medical facility as the patient at the time of diagnosis, and whose registration numbers were closest to that of the patient, were identified. The date of diagnosis and control selection which was specified for the triplet, was called the index date for convenience.

The medical records for 40 years (mean) prior to the index date on cases, and 41 years (mean) on the controls were reviewed. The records were also evaluated after the index date up to the end of 1979, or the death of the patient. Information on smoking habits and acute and chronic illnesses was obtained in cases and controls. Diagnosis of a chronic illness was considered valid only when it was made on at least two separate occasions. A total of 89 diagnostic categories were identified and compared in patients and the controls. History of drug therapy for parkinsonism was noted, and the date and cause of death was identified where appropriate.

\section{ResUlts}

During the 13 years, 138 new parkinsonian cases were identified among Rochester citizens. The annual age and sex adjusted (to 1970 U.S. population) incidence rate was estimated at 20.5/ 100,000 . There was no significant difference between males and females. There was no case in whom the diagnosis was made

From the Department of Clinical Neurological Sciences. University Hospital, Saskatoon.

Reprint requests to: Dr. A.H. Rajput, Department of Clinical Neurological Sciences, University Hospital, Saskatoon, Saskatchean, Canada S7N 0X0 
before age 30 , while the peak incidence occurred between age 75 and 84 years. The most common type of parkinsonism was idiopathic (85.5\%), followed by drug-induced (7.2\%). Smoking habits of patients and their controls prior to the index date are compared in Figure 1. There was no significant difference between patients and the controls who had never smoked prior to the index date. Other illnesses that were significantly more common among the patient or their controls before the index date are shown in Figure 2. Dementia was diagnosed more frequently among the cases than the controls $(P=0.048)$ before the index date. By end of five years after the index date, a new diagnosis of dementia was also made more often in cases (18.4\%) than in the controls (5.5\%) (Figure-3).

Mortality rate was significantly higher (1.6 to 1 ) among the patients than the controls (Figure 4). Only $69(50 \%)$ cases were treated with levodopa. There were no predetermined criteria for withholding the drug, but from the review of medical records it was felt that those who did not receive levodopa were in poorer general health compared to those who did. When the

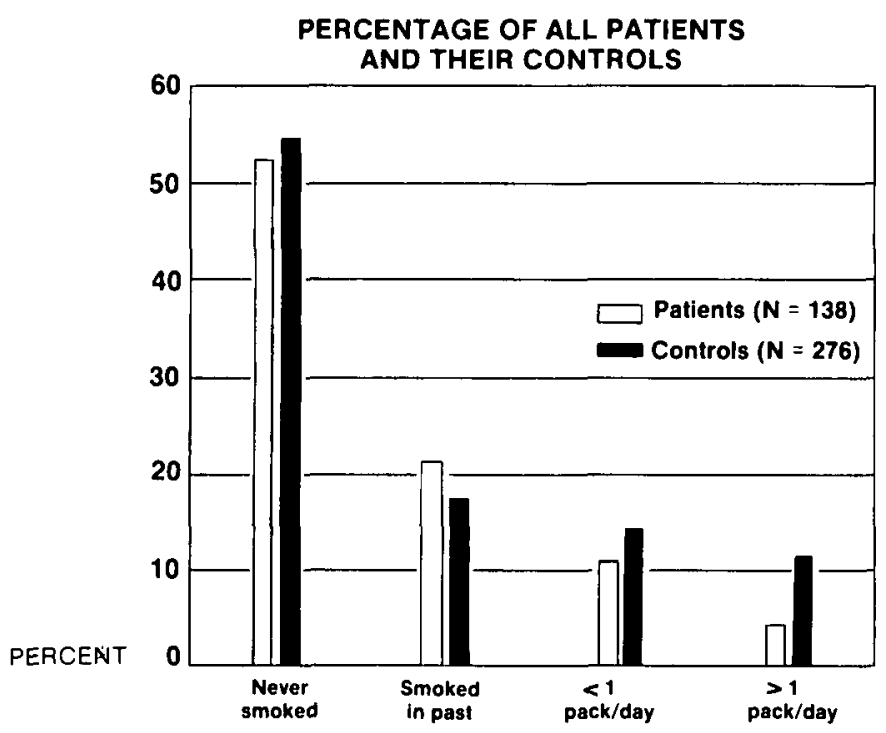

Figure 1 -Smoking habits in patients and 2 age- and sex-matched controls prior to the index date. There is no difference in the two groups.

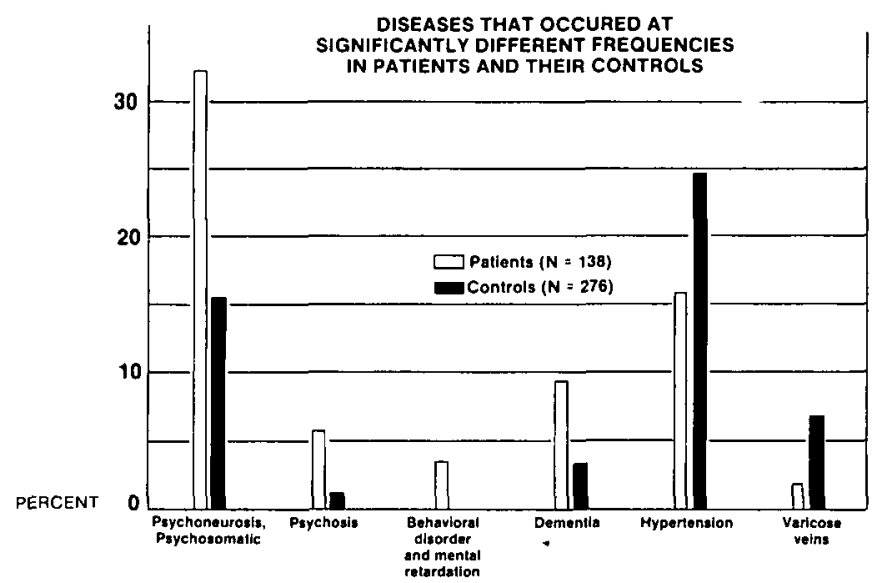

Figure 2-Other diagnoses that were statistically different among patients and 2 age-and sex-matched controls before the index date. Hypertension and varicose veins occurred less frequently in cases than the controls. mortality rate in patients treated with levodopa was compared with their controls, no significant difference was noted. The levodopa-treated group on the other hand manifested a significantly higher frequency $(P=0.035)$ of dementia compared to their controls.

\section{Discussion}

I will briefly compare these data with some previous epidemiological studies. Table 1 shows incidence rates of parkinsonism in the Rochester population observed in three different studies between 1935 and 1979. The first study (Kurland, 1958) dealt with the period 1945 to 1954 and noted an annual incidence rate of 20/100,000. The second study by Nobega et al. (1967) covered the years 1935 to 1966 and reported an annual incidence rate of $18.5 / 100,000$. Neither of these studies included drug-induced cases. Since drug-induced parkinsonism was first recognized in the 1950s, exclusion of these cases from the previous studies is understandable. In the present study, the annual incidence rate for the entire parkinsonian population is $20.5 / 100,000$. Even if

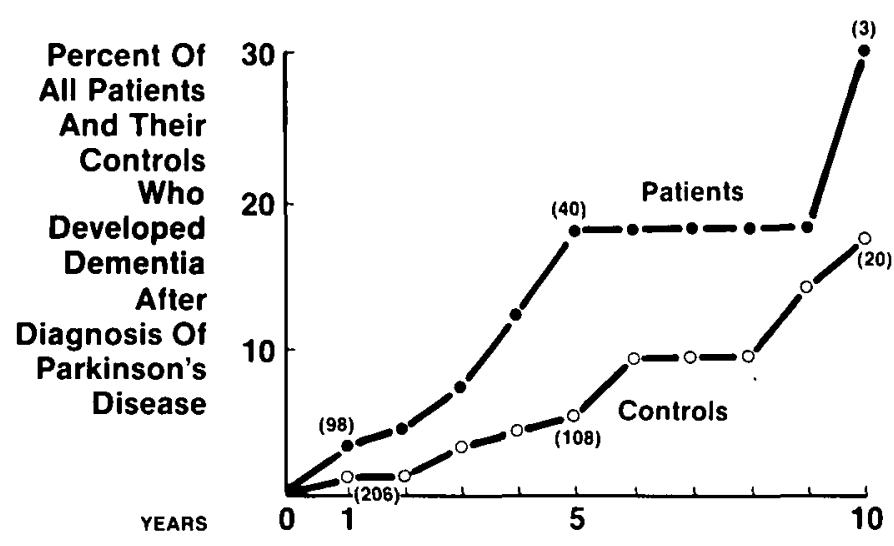

PATIENTS ( $=119)$

CONTROLS $(N=238)$

Figure 3 - New cases of dementia after the index date among cases and two matched controls.

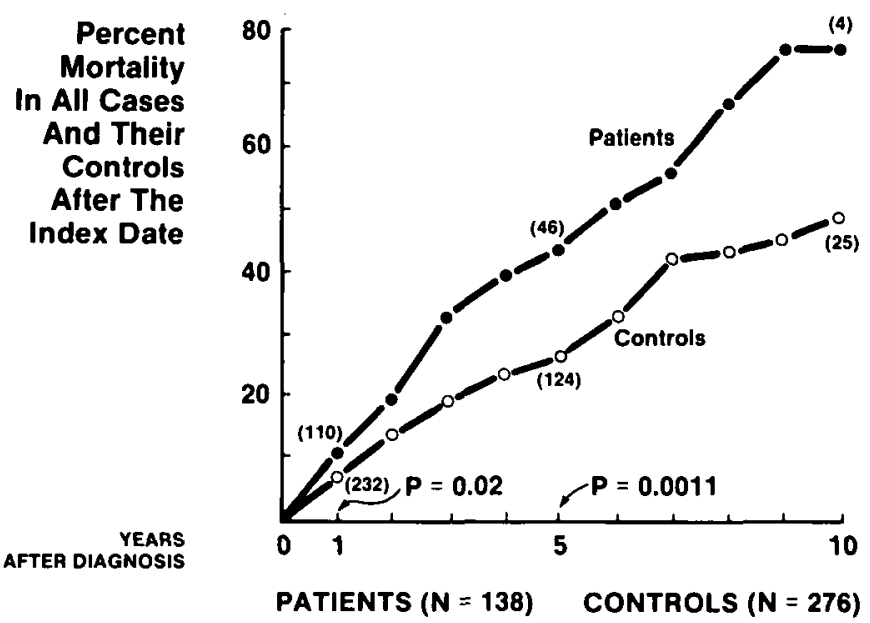

Figure 4-Mortality rate in all cases and 2 age-and sex-matched controls. "Significantly lower survival in cases than the controls is seen. 
we exclude the drug-induced cases, the incidence rate is $18.2 / 100,000$ - virtually unchanged from previous reports. Exclusion of drug-induced parkinsonism however can no longer be justified as it constitutes the second largest group of Parkinson syndrome today and a number of these patients suffer from pre-clinical idiopathic Parkinson's disease (Rajput et al., 1982; Goetz, 1983).

A negative association between smoking and parkinsonism was first suggested by Hammond (1966) and by Kahn (1966). Table 2 is a brief summary of some of the papers dealing with smoking habits of parkinsonian patients. While several studies suggest that cigarette smoking might have a protective effect against parkinsonism, Haack et al. (1981), in a detailed analysis of nicotine consumption, concluded that the lifetime exposure prior to onset of Parkinson's disease in the patients and controls is similar. Smoking habits prior to onset of parkinsonism in our study were not significantly different from the controls. It is therefore concluded that cigarette smoking does not have a protective effect against parkinsonism.

Dementia among the cases was significantly more common than among the controls $(P=0.048)$ before the index date. The age at diagnosis of dementia in the cases and controls was not significantly different. These data indicate that when other factors such as age and effect of drugs are excluded, there is strong correlation between parkinsonism and dementia. By the end of five years after the index date nearly three times more new cases of dementia were recognized among patients (18.5\%) than among their controls (5.5\%). When the sub-groups receiving different anti-parkinsonian drugs, or no drugs for parkinsonism, were compared with their respective controls, only those treated with levodopa developed dementia more frequently $(\mathrm{P}=0.035)$ than their controls. Because there were no fixed criteria for

Table 1: Annual incidence of parkinsonism per 100,000 population in Rochester, Minnesota (1935-1979)

\begin{tabular}{|c|c|c|}
\hline Author & Period of Study & Incidence \\
\hline Kurland (1958) & $1945-54$ & $\begin{array}{l}20 \text { (adjusted to } 1950 \text { U.S. } \\
\text { population) }\end{array}$ \\
\hline Nobrega et al. (1967) & $1935-66$ & $\begin{array}{l}18.5 \text { (adjusted to } 1960 \text { U.S. } \\
\text { population) }\end{array}$ \\
\hline Present study & $1967-79$ & $\begin{array}{l}20.5 \text { (adjusted to } 1970 \text { U.S. } \\
\text { population) }(18.2)^{*}\end{array}$ \\
\hline
\end{tabular}

*Incidence rate in the present study when drug-induced cases are excluded.

Table 2: Relationship between smoking and Parkinson's disease

\begin{tabular}{cc}
\hline Author & Conclusions \\
\hline Hammond (1966) & Cases smoked less frequently than expected
\end{tabular}

in general population. (death certificates)

Kahn (1966) Cases smoked less frequently than expected in general population. (death certificates)

Bauman et al. (1980) Before onset of parkinsonism patients smoked less than selected controls.

Haack et al. (1981) Total nicotine exposure prior to onset of Parkinsonism similar in cases and controls.

Present study similar in cases and their controls.

\begin{tabular}{lc}
\hline \multicolumn{2}{c}{ Table 3: Post-encephalitic parkinsonism in Rochester, Minnesota } \\
\hline Date & Percentage of Parkinsonian Cases \\
\hline $1.1,1955$ & $20 \%$ \\
$1.1,1965$ & $6.6 \%$ \\
$1967-1979$ & No new cases diagnosed. \\
\hline
\end{tabular}

Table 4: Mortality in parkinsonian patients

\begin{tabular}{lcl}
\hline \multicolumn{1}{c}{ Author } & Period & Relative Risk (cases to controls) \\
\hline $\begin{array}{l}\text { Nobrega et al. (1967) } \\
\text { (Rochester population) }\end{array}$ & $1935-66$ & $\begin{array}{l}1.6 \text { to I (expected in comparable } \\
\text { population). }\end{array}$ \\
$\begin{array}{l}\text { Present study } \\
\text { (Rochester population) }\end{array}$ & $1967-79$ & $\begin{array}{l}1.6 \text { to I (compared to 2 age- and } \\
\text { sex-matched controls). } \\
\text { Hoehn \& Yahr }\end{array}$ \\
$\begin{array}{l}\text { 3 to 1 (expected in comparable } \\
\text { (New York) }\end{array}$ & population). \\
\hline
\end{tabular}

using levodopa this observation could be attributed to bias of case selection for treatment.

Poskanzer and Schwab, (1963) suggested that Parkinson's disease was caused by exposure to Von Economo encephalitis agent between 1918 and the early 1930's. If that hypothesis were correct we would expect a drop in incidence of parkinsonism after about 1970. Table 3 shows the pattern of postencephalitic parkinsonism in Rochester population. While in 1955 these cases constituted $20 \%$ of parkinsonian population, by 1965 they accounted for only $6 \%$ of parkinsonism and there were no new cases between 1967-79. Absence of new post-encephalitic cases, coupled with nodecline in incidence of parkinsonism, are strong indications against Cohort hypothesis as the explanation for etiology of Parkinson's disease.

Mortality rate among the patients was significantly higher than the control population (Figure 4). Relative risk of mortality among cases was 1.6 times higher than in the controls. This observation is identical to that reported by Nobrega et al., (1967) in the same population previously (Table 4). We noted that the mortality rate among the levodopa-treated group was not significantly different from that in their controls. This could be attributed to an artifact of case selection for treatment as only $50 \%$ of the cases received levodopa therapy. There is no community-based study dealing with the proportion of patients treated with levodopa but there is no doubt that in every community a significant percentage of cases are not treated with that drug for a variety of reasons. Our data on mortality rate cannot be compared with the observations made by Hoehn and Yahr, (1967) as they studied a neurological referral population, while the Rochester studies include all parkinsonian cases regardless of severity of illness, and whether or not they were evaluated by a neurologist. Our data indicate that no change in mortality pattern has occurred since introduction of levodopa.

\section{REFERENCES}

Baumann RJ, Jameson HD, McKean HE, Haack, DG, Weisberg LM (1980) Cigarette Smoking and Parkinson's Disease. 1. A comparison of cases with matched neighours. Neurology 30:839-43.

Cotzias GC (1971) Levodopa in the Treatment of Parkinsonism. J.A.M.A. Vol. 218, No. 13: 1903-1908.

Goetz CG (1983) Drug-Induced Parkinsonism and Idiopathic Parkinson's Disease. Arch. Neurol. 40:325-326. 
Haack DG, Baumann RJ, McKean HE, Jameson HD, Turbeck JA (1981) Nicotine Exposure and Parkinson's Disease Amer. J. of Epidemiology 114:2:191-200.

Hammond EC (1966) Smoking in Relation to the Death Rates of One Million Men and Women. In Epidemiological Study of Cancer and Other Chronic Disease. National Cancer Institute Monograph No. 19. Washington, D.C.: U.D. Government Printing Office: 127-204.

Hoehn MM, Yahr MD (1967) Parkinsonism: Onset, Progression, and Mortality. Neurology, 17:427-442.

Kahn HA (1966) Smoking in Relation to the Death Rates of One Million Men and Women. In Epidemiological Study of Cancer and Other Chronic Disease. National Cancer Institute Monograph No. 19. Washington, D.C.: U.S. Government Printing Office: 1-125.
Kurland LT (1958) Epidemiology: Incidence, Geographic Distribution, and Genetic Considerations. In Field W. (ed.): Pathogenesis and Treatment of Parkinsonism. Charles C. Thomas, Springfield, Illinois: 5-43.

Nobrega FT, Glattre E, Kurland LT, Okazaki H (1967) Genetics and Epidemiology of Parkinson's Disease. In Barbeau A, Brunnette JR (eds.): Progress of Neurogenetics. Excerpta Medica Foundation, Amsterdam: 474-485.

Poskanzer DC, Schwab RS (1963) Cohort Analysis of Parkinson's Syndrome: Evidence for a Single Etiology Related to Sub-Clinical Infection About 1920. J Chr. Dis. 16: 961-973.

Rajput AH, Rozdilsky B, Hornykiewicz O, Shannak K, Lee T, Seeman P (1982) Reversible Drug Induced Parkinsonism. Clinicopathological Study of two cases. Arch. Neurol., 39:644-646. 